\section{Canadian Food Studies}

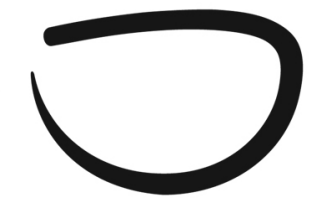

La Revue canadienne des études sur l'alimentation

Commentary

\title{
Is it hot in here, or is it just me? On being an emotional academic
}

\author{
David Szanto
}

University of Gastronomic Sciences, Pollenzo, Italy

At many moments during the 2015 Canadian Association for Food Studies (CAFS) Assembly last May, I found myself becoming quite emotional. In fact, I will amend that statement: I didn't just become emotional, I let myself both feel and express my emotions, in public, to myself and to all those who might have been paying attention.

It happened during the Pre-Conference, when we collectively realized there were more students and emerging scholars in attendance than the total participation for the first CAFS conference in 2006. It happened in the What IF? Symposium, as I watched a presentation about how science and technology studies might benefit from food studies (and vice versa), and the power and poetics that are already at the intersections of STS and food. It happened when I was giving a talk myself, about a few what-iffy ideas for future epistemic models, and the potential for fermentation and actor-network theory and performance to help us reimagine food systems, death, and humanity. And it of course happened when Alice Julier gave her rousing - and very personal-political—symposium keynote address, swirling together labour, feminism, and food.

In writing this, I feel as if I am somehow coming out as an "emotional academic". As if it were a thing I have been trying to keep hidden (not very successfully, probably) over the years. Yet I also suspect this label is one with which many of us might self-identify. Moreover, I believe that we need to own our emotionality when it comes to food scholarship, and to find ways to incorporate it actively into our work. Certainly, food is an emotional, personal, and intersubjective topic, and so perhaps these qualities should be woven into the theoretical foundations and methodological practices of the field. 
For some, I may seem late to the game in embracing subjectivity; for others, it may contradict what they consider to be the nature of academic work. Historically, certainly, scholars have been looked to as the cool rationalists of the world, unswayed by feeling, faith, and fancy, but guided by principles of reason and, above all, objectivism. The so-called scientific method has clearly been a paradigm for many disciplines that undergird food studies, allowing us to create distance and differentiation from our study object, rather than getting too mired in its messy, tasty, and intimate realities. But is this helping us as knowledge seekers, hurting us, or both? And more specifically, when and how is the "messiness" of academic emotionalism important?

Many years ago, while immersed in a master program centered on food culture and communications, I found myself in conversation with a respected and imaginative professor of geography. It was probably after a nice meal of some sort, and we were musing on the nature of food studies, relative to certain longer-established fields. At one point, I said something to the effect of: "Well, all academic work is personal, after all.” It was an opinion I had held long before starting the master, formed after thirty-five years observing the academics around me. (Both my parents were professors, and I was frequently in the presence of their colleagues and graduate students.)

The geographer looked a little horrified at my statement, and quickly shot back, "I should certainly hope not.” It surprised me, since she had seemed to be one of the more nonconventional researcher-thinker-doers I had met. Later, however, I realized she must have thought that I meant something quite different than what I intended. I had wanted to express that if one devotes a great deal of time and attention to a given subject—as most academics do — then it must be personally compelling, regardless of the rigor or looseness of one's approach. I think she thought that I meant it was all about her.

Ten years have passed since that exchange, and a new sense of what I mean when I call for academia to be "personal” is starting to emerge. It means finding ways to acknowledge the researcher's whole corpus within her work, to take advantage of the benefits of emotion-plusreason, and to accommodate the many shifts that are taking place in our industry.

Particularly in the field of food, students appear to be initiating upper-level degrees for increasingly diverse reasons. Graduate work may now be done in order to transform the individual as a citizen, not just into a writer of scholarly articles and a giver of lectures. It may be a way to construct one's self as an agent of change in the world, or simply to find and follow different paths than those generally in evidence. The more-conventional academic attitude of I-consider-this-a-critically-important-subject is doubtless still relevant, but so might be others, such as I-need-to-understand-where-and-how-I-belong-in-this-world. Regardless of whether the latter is part of a broader trend towards self-reflection and egocentrism [insert Facebook blame statement here], it is an attitude that is undeniably present - and immovable-among the bachelor and master students I have taught. What is more, having gone through these selfexaminations and transformations, many graduates become motivated to induce similar change 
within the worlds around them, sometimes just so that they have a space in which they can continue to belong. More power to them.

In addition to the drivers that put master and doctoral bums in seats, increasing criticality and reflexivity in certain academic fields and area studies have also helped draw attention to the influence of the self in research outcomes. Many of these scholarly areas are about reimagining the notion of "reality" and challenging the historic intentions of those who have framed our teaching and learning models. Whether one calls it wishful thinking, prescience, or just more what iffery, I perceive this movement as a personal turn, one that is manifesting itself with increasing frequency. If indeed it exists, our social and professional institutions are going to have to find ways to accommodate and respond to it. Ignored or repressed, it will simply claw itself to the surface with more vigor (emotionally driven vigor, of course).

Assuming for the moment that this nascent turn is upon us, consider three characteristics of academia that seem to be contributing factors. First, universities are churning out way too many $\mathrm{PhD}$ graduates for the academic pipeline to absorb. Knowing this going in, many doctoral applicants pre-figure their projects as personally driven, explorations of a given subject for the purposes of individual enlightenment and growth, rather than a means of "getting into the academic club”. Clearly, the objective of the majority of PhD students can no longer be a tenuretrack position, nor even necessarily to become an academic. As our institutions continue to welcome more and more graduate students, it means welcoming those people's diverse motivations. It also means that supervisors, funding structures, program directors, and the bureaucracies of academia will have to make room for processing emotionality and other personal factors, rather than expecting all students to be aiming at the same academic gold. In parallel, there is an intriguing opportunity: what kind of institutions outside of academia (that is, other than government, NGOs, and industry) might be populated (or created) as professional spaces for these eventual "non-academic" doctorate holders?

Second, and following various turns toward reflexivity, many areas of academic practice are already absorbing the personal through engagement with corporeality, affect, and the psyche. Certain streams of anthropology, political science, gender studies, art and design, performance, geography, and sociology recognize that researchers are components of their own research apparatuses. This means not only the physical body, but also the habitus, cognitive experience, sensory histories, and the limbic system are all entangled with the theoretical and methodological tools that comprise a given project. If all these "parts" of the researcher are part of how research is done, then once again the academy and individual academics will have to learn to deal with that package. We cannot assume that our emotions are separate from our intellects, or that our minds can be made to work when our bodies are not well. While these old dualities are frequently acknowledged "in theory", the practicalities (including the timelines) of doing a chunk of research or writing often lead us to forget that humans are whole systems, not bifurcated beings. Supervisors and colleagues get impatient, administrative processes are unresponsive, journal editors too quickly dismiss fuzzy textual explorations. Even our own 
internal voices tell us to just get on with it. When these institutional elements make institutional demands, even the most carefully constructed theory-and-practice hybrid can lose its lovely integrity.

Third, as we attend to the effects of our work in the larger ecologies of which we are a part, the line between scholarship and political action becomes increasingly blurred. Certainly many food scholars over the years have supported revolutions, but activism seems particularly prevalent (and importantly so) among those entering food studies more recently. Driven to enact change in the world, and hoping for the legitimacy that graduate degrees often confer, both master and doctoral students now frequently view academia as a means to activist ends. Once again, the personal, political, and professional become entangled, not only with each other, but with the linked processes of thinking and doing about food. For the academic institution-as well as organizations like CAFS - it requires accepting that students are already hybridized as they come in to our folds, as well as making the appropriate institutional adjustments to support and encourage such people. Moreover, it means that students and emerging scholars will be constructing and occupying many non-separated spaces during their careers, which will demand ongoing flexibility for our disciplinary framings. Given the power structures that characterize and sustain most universities, productively accommodating students who are politically and critically attentive will require a good deal of self-examination on the part of senior scholars, administrators, and other institutional actors. Equally, it means listening to the voices in our hearts (and not just heads), while resisting the muzzles we may be tempted to self-impose.

After the CAFS Assembly in Ottawa, I traveled southward to the ASFS/AFHVS conference in Pittsburgh, where my emotionality continued to perform me. I shared accounts of my post-dissertation defense depression. I jumped up and down with glee when historic power structures got rattled, and when both Jell-O and chia slyly evaded foodish categorization. I got a little steamed when I felt that the material agency of knives and onions was getting short shrift in a presenter's research methodology. I did all this because, frankly, I am emotional about these issues. They are things I care about-a lot. But partly, I also let it show in order to see what would happen. I wanted to know what being out as an emotional academic would do to my own sense of professionalism, and I wanted to perceive the responses of the people who bore witness. Reactions were predictably multiple: looks of confusion, empathy, mild revulsion, blankness. (Relief, too, for surely there are other "closeted emotionals" among us....) Over the course of the conference I felt more vulnerable than I generally do in such settings, but also much more relaxed - and more honest. For me, anyway, the experiment was a success.

Clearly, in professional contexts such as universities, emotion isn't easy, either to be exposed to or to feel. Yet it is always already a part of each one of us, never separate from our whole corpus, and deeply integrated with the common fascination we share for our subject. Being emotional doesn't weaken us as academics or take away from the ways in which we are intellectual about food; the two are not inversely related. Emotion and intellect complement one another. Emotions make us more sensitive to why our research is important to us and to 
humanity, more mindful about how our colleagues operate and feel, and more capable of coming into resonance with the extraordinary complexity of food issues.

I tend to suspect that I'm not the only one feeling a little warm lately. If we are to grow and develop the way our field examines and deals with the all-important subject of food, then let us activate the personal turn in a broader way. Let us productively come to grips with our emotional states as human academics. I am sure that we are more than capable of doing so, of accommodating — and indeed benefiting from - emotionality and intersubjectivity in our research, reporting, and responses to one another. Moreover, I can imagine a day when this active integration of all that we are allows food study to take the lead in academia, as a paradigm for integrated and holistic scholarship that is both personal and personal. 